\title{
EFEKTIVITAS AIR PERASAN DAUN ALPUKAT (Persea americanaMill.)TERHADAP KEMATIAN LARVA NYAMUK Aedes aegypty
}

\author{
Oktaviana Krissanti, Setiawan, Koerniasari
}

\begin{abstract}
ABSTRAK
Pengendalian vektor menggunakan insektisida kimia secara terus menerus dapat menyebabkan serangga resisten . Alternatif untuk mengurangi dampak negatif dari insektisida kimia yaitu menggunakan insektisida nabati yang berasal dari bahan alami yaitu daun alpukat. Kandungan kimia daun alpukat adalah alkaloid, flavonoid, saponin, dantanin. Tujuan dari penelitian ini adalah untuk mengetahui konsentrasi efektif air perasan daun alpukat (Persea americana Mill.) terhadap kematian larva Aedes aegypty.

Jenis penelitian ini merupakan penelitian eksperimental murni dengan rancangan posttest only control group design. Penelitian menggunakan 6 perlakuan dengan konsentrasi $0 \%$ (sebagai kontrol), 7,5\%, 10\%, 12,5\%, 15\% dan 17,5\% dengan 3 kali pengulangan. Penelitian menggunakan 450 ekor larva nyamuk Aedes aegypty instar III dan dibagi 25 ekor larva untuk masing-masing kelompok dalam $100 \mathrm{ml}$ aquades dengan pengamatan selama 24 jam. Analisis data silakukan secara analitik menggunakan uji probit dan uji beda (kruskan wallis).

Hasil uji menunjukkan terdapat perbedaan yang signifikan antara kelompok kontrol dan air perasan daun alpukat terhadap kematian larva $(p=0,000)$. Analisis probit didapatkan LC $_{50}$ pada konsentrasi air perasan daun alpukat 10,624\%. Dari hasil tersebut menunjukkan air perasan daun alpukat efektif dalam membunuh larva nyamuk Aedes aegypty.

Saran yang dapat diberikan adalah adanya penelitian lebih lanjut mengenai cara menghilangkan warna pada air yang diberi air perasan daun alpukat.

Kata kunci : Air perasan daun alpukat, Larvasida nabati, Larva Aedes aegypty.
\end{abstract}

\section{A. Pendahuluan}

Nyamuk Aedes aegypti merupakan salah satu vektor penyebab penyakit Demam Berdarah Dengue (DBD). Berdasarkan data dari Direktorat Pencegahan dan Pengendalian Penyakit Tular Vektor dan Zoonotik, Kemenkes RI bahwa semenjak tahun 2014 hingga 2016 jumlah kasus penyakit DBD mengalami kenaikan setiap tahunnya. Di tahun 2017 terhitung sejak Januari hingga Mei tercatat sebanyak 17.877 kasus dengan 115 kematian (Laporan Departemen Kesehatan, 2017).
Berdasarkan data yang diperoleh mengenai penyakit DBD dari Dinas Kesehatan Provinsi Jawa Timur, di 38 Kota selama 3 tahun terakhir yaitu pada tahun 2015 ditemukan sebanyak 20.129 kasus dengan 283 kematian $(\mathrm{CFR}=1,41 \%)$, kemudian pada tahun 2016 terjadi peningkatan kasus yaitu sebanyak 24.461 kasus dengan 356 kematian ( $C F R=1,46 \%)$, selanjutnya pada tahun 2017 terhitung sampai dengan bulan November terdapat kasus sebanyak 6.110 kasus dan 91 
diantaranya meninggal dunia atau CFR sebesar 1,49\% (Dinkes Jatim, 2017). Sedangkan menurut data sekunder Dinas Kesehatan Kota Surabaya mengenai penyakit DBD di 31 Kecamatan pada tahun 2016 ditemukan 938 kasus dengan 7 kematian $\quad$ (CFR $=0,75 \%) \quad$ (Dinkes Surabaya, 2016).

Pencegahan penyakit yang dapat dilakukan yaitu dengan pengendalian vektor penyakit. Pengendalian vektor masih banyak menggunakan insektisida kimia karena efektif dan hasilnya dapat diketahui secara cepat. Penggunaan insektisida kimia dalam pengendalian vektor memiliki dampak negatif dan positif (Felix, 2008). Apabila penggunaan insektisida dalam waktu lama untuk sasaran yang sama dapat menyebabkan berkembangnya populasi jentik Aedes aegypti menjadi resisten lebih cepat (Boewono, et al, 2012).

Saat ini masyarakat menggunakan larvasida abate (temephos) untuk membunuh larva Aedes aegypti sudah lebih dari 30 tahun (Nugroho, 2011). Namun dalam penggunaan temephos sebagai larvasida menunjukkan adanya resistensi dibeberapa wilayah. Prasetyowati dkk (2016) melaporkan bahwa Aedes aegypti di tiga Kotamadya DKI Jakarta telah resisten dengan temephos dan malathion, serta Sukesi dan Surahma (2007) melaporkan bahwa jentik Aedes aegypti di Kecamatan Wirobrajan Kota Yogyakarta menunjukkan penurunan status kerentanan dari rentan menjadi resisten sedang. Hal tersebut terjadi kemungkinan karena lamanya penggunaan, dosis yang digunakan dan waktu penggunaannya tidak teratur.

Berkaitan dengan dampak negatif yang disebabkan oleh penggunaan insektisida secara terus-menerus, maka diperlukan suatu alternatif pembunuh larva yang berasal dari bahan alami untuk mengurangi pemakaian insektisida kimia. Salah satu alternatif yang dapat digunakan adalah tumbuhan alpukat.

Berdasarkan hal tersebut, peneliti tertarik melakukan penelitian dengan judul "EFEKTIVITAS AIR PERASAN DAUN ALPUKAT (Persea americana Mill.) TERHADAP KEMATIAN LARVA NYAMUK Aedes aegypty"

\section{B. Metode Penelitian}

Jenis penelitian ini adalah eksperimental murni dengan rancanganposttest only control group design. Penelitian menggunakan 6 perlakuan dengan konsentrasi $0 \%$ (sebagai kontrol), 7,5\%, 10\%, 12,5\%, $15 \%$ dan $17,5 \%$ dengan 3 kali pengulangan. Penelitian menggunakan 450 ekor larva nyamuk Aedes aegypty instar III dan dibagi 25 ekor larva untuk masing-masing kelompok dalam $100 \mathrm{ml}$ aquades dengan pengamatan selama 24 jam. Analisis data silakukan secara analitik menggunakan uji probit dan uji beda (kruskan wallis).

\section{Hasil Penelitian}

1. Pengukuran $\mathrm{pH}$, Suhu, dan Kelembaban 
Tabel 1

HASIL RATA-RATA PENGUKURAN PH DAN SUHU MEDIA

\begin{tabular}{ccc}
\hline Konsentrasi & Suhu $\left({ }^{\circ} \mathbf{C}\right)$ & $\mathbf{p H}$ \\
\hline Kontrol & 26,5 & 7 \\
\hline $7,5 \%$ & 26,5 & 7 \\
\hline Konsentrasi & Suhu $\left({ }^{\circ} \mathbf{C}\right)$ & $\mathbf{p H}$ \\
\hline $10 \%$ & 26,5 & 7 \\
\hline $12.5 \%$ & 26,5 & 7 \\
\hline $15 \%$ & 26,5 & 7 \\
\hline $17.5 \%$ & 26,5 & 7 \\
\hline
\end{tabular}

Berdasarkan hasil penelitian pada Tabel 1 didapatkan nila $\mathrm{pH}$ pada media perkembangbiakan larva nyamuk Aedes aegypty pada kontrol dan media air dengan pemberian air perasan daun alpukat (Persea americana Mill.) adalah sama yaitu 7. Rata-rata suhu pada media air kontrol dan media air dengan pemberian air perasan daun alpukat
(Persea americana Mill.) adalah 26,5 ${ }^{\circ} \mathrm{C}$. Hal tersebut sesuai dengan kadar $\mathrm{pH}$ untuk kehidupan larva nyamuk Aedes aegypty berkisar antara 5,8-8,6 dan suhu air yang dapat mempengaruhi kematian larva Aedes aegypty pada kisaran $<25^{\circ} \mathrm{C}$ atau $>$ $32^{\circ} \mathrm{C}$ (Arifin dkk, 2013).

\section{Tabel 2}

HASIL RATA-RATA PENGUKURAN SUHU UDARA DAN KELEMBABAN

\begin{tabular}{ccc}
\hline Waktu & Suhu $\left({ }^{\circ} \mathbf{C}\right)$ & Kelembaban (\%) \\
\hline 24 jam & 26,4 & 64 \\
\hline
\end{tabular}

Berdasarkan hasil penelitian pada Tabel 2 didapatkan nilai suhu udara ruangan penelitian adalah $26,4^{\circ} \mathrm{C}$ yang berarti sudah sesuai dengan suhu optimum untuk pertumbuhan nyamuk adalah $25-27^{\circ} \mathrm{C}$ dan pertumbuhan nyamuk akan berhenti sama sekali bila suhu $<10^{\circ} \mathrm{C}$ atau $>40^{\circ} \mathrm{C}$ (Gandham,
2013). Untuk rata-rata tingkat kelembaban ruangan penelitian adalah $64 \%$ yang berarti sudah sesuai untuk keadaan yang kondusif bagi nyamuk Aedes aegypty berkembangbiak yaitu berkisar 60\%-80\% (Arifin dkk, 2013). 
2. Jumlah Kematian Larva Nyamuk Aedes aegypty

Tabel 3

JUMLAH KEMATIAN LARVA NYAMUK AEDES AEGYPTY DENGAN PEMBERIAN

AIR PERASAN DAUN ALPUKAT (Persea americana Mill.) SELAMA 24 JAM

\begin{tabular}{|c|c|c|c|c|c|}
\hline \multirow[b]{2}{*}{$\begin{array}{c}\text { Konsentra } \\
\text { si }\end{array}$} & \multirow{2}{*}{$\begin{array}{l}\text { Jumlah } \\
\text { Larva Uji } \\
\text { (Ekor) }\end{array}$} & \multicolumn{3}{|c|}{ Kematian Larva } & \multirow[b]{2}{*}{ Persentase } \\
\hline & & $\begin{array}{l}\text { Replika } \\
\text { si } 1\end{array}$ & $\begin{array}{l}\text { Replikas } \\
\text { i } 2\end{array}$ & $\begin{array}{c}\text { Replikas } \\
\text { i } 3\end{array}$ & \\
\hline $0 \%$ & 25 & 0 & 0 & 0 & $0 \%$ \\
\hline $7,5 \%$ & 25 & 17 & 13 & 16 & $61,3 \%$ \\
\hline $10 \%$ & 25 & 19 & 21 & 18 & $77,3 \%$ \\
\hline $12.5 \%$ & 25 & 25 & 24 & 24 & $97,3 \%$ \\
\hline \multirow{2}{*}{$\begin{array}{c}\text { Konsentra } \\
\text { si }\end{array}$} & Jumlah & \multicolumn{3}{|c|}{ Kematian Larva } & \\
\hline & $\begin{array}{l}\text { Larva Uji } \\
\text { (Ekor) }\end{array}$ & $\begin{array}{l}\text { Replika } \\
\text { si } 1\end{array}$ & $\begin{array}{c}\text { Replikas } \\
\text { i } 2\end{array}$ & $\begin{array}{c}\text { Replikas } \\
\text { i } 3\end{array}$ & Persentase \\
\hline $15 \%$ & 25 & 25 & 25 & 25 & $100 \%$ \\
\hline $17.5 \%$ & 25 & 25 & 25 & 25 & $100 \%$ \\
\hline
\end{tabular}

Penelitian ini menggunakan kelompok kontrol yaitu menggunakan $100 \mathrm{ml}$ aquades. Berdasarkan pengamatan yang dilakukan selama 24 jam didapatkan hasil bahwa tidak terdapat kematian larva yang berarti aquades tidak menyebabkan kematian pada larva uji. Hal tersebut dikarenakan aquades ataupun air merupakan habitat larva nyamuk Aedes aegypty dan tidak memiliki kandungan toksik (Heriyanto dkk, 2011).

Kematian larva nyamuk Aedes aegypty terdapat pada semua kelompok perlakuan yang diberikan air perasan daun alpukat (Persea americana Mill.). Berdasarkan pada hasil penelitian Pada Tabel 3 menunjukkan bahwa terjadi peningkatan rata-rata kematian larva nyamuk Aedes aegypty seiring dengan peningkatan konsentrasi air perasan daun alpukat (Persea americana Mill.). Kematian larva paling rendah berada pada konsentrasi 7,5\% dimana terdapat $61,3 \%$ larva yang mati dan kematian paling tinggi berada pada konsentrasi $15 \%$ dan $17,5 \%$ dimana terdapat $100 \%$ larva yang mati. Hal diatas menunjukkan perbedaan konsentrasi air perasan daun alpukat (Persea americana Mill.) mempengaruhi jumlah kematian larva. Sehingga kematian larva berbanding lurus dengan besarnya konsentrasi yang diberikan pada larva nyamuk Aedes aegypty, yang artinya semakin besar konnsentrasi yang diberikan maka semakin cepat terjadinya kematian larva nyamuk Aedes aegypty. Hal ini membuktikan bahwa insektisida untuk membunuh serangga tergantung pada bentuk, cara masuk ke dalam badan serangga, macam bahan kimia, konsentrasi, dan jumlah (dosis) insektisida (Sutanto, 2008). 
3. Nilai $\mathrm{LC}_{50}$ Air Perasan Daun Alpukat (Persea americana Mill.) terhadap Kematian Larva Nyamuk Aedes aegypty

\section{Tabel 4}

HASIL NILAI LC 50 AIR PERASAN DAUN ALPUKAT (Persea americana Mill.) TERHADAP KEMATIAN LARVA NYAMUK AEDES AEGYPTY

\begin{tabular}{ccc}
\hline Estimate & Lower & Upper \\
\hline 10,624 & 0,727 & 12,214
\end{tabular}

Berdasarkan Tabel V.4 dari hasil Nilai LC dibawah $\mathrm{LC}_{50}$ dikategorikan pengujian air perasan daun alpukat memiliki daya bunuh rendah, dan nilai (Persea americana Mill.) terhadap $\mathrm{LC}$ diatas $\mathrm{LC}_{50}$ dikategorikan memiliki kematian larva nyamuk Aedes aegypty daya bunuh yang efektif. Semakin didapatkan hasil bahwa $\mathrm{LC}_{50}$ terdapat rendah nilai $\mathrm{LC}_{50}$ suatu zat tersebut pada konsentrasi $10,624 \%$ dengan mempunyai aktivitas yang lebih tinggi interval $0,727 \%-12,214 \%$. Hal dalam membunuh hewan uji, karena zat tersebut menunjukkan bahwa tersebut perlu konsentrasi yang lebih konsentrasi yang dapat membunuh $50 \%$ rendah untuk memaatiikan hewan uji larva nyamuk Aedes aegypty yaitu (Haditomo, 2010). konsentrasi $10,624 \%$.

4. Analisis Konsentrasi Air Perasan Daun Alpukat (Persea americana Mill.) terhadap Kematian Larva Nyamuk Aedes aegypty sebagai Biolarvasida

\section{Tabel 5}

HASIL UJI BEDA (Kruskal Wallis) BERBAGAI KONSENTRASI AIR PERASAN DAUN ALPUKAT (Persea americana Mill.) TERHADAP KEMATIAN LARVA NYAMUK AEDES AEGYPTY

\begin{tabular}{cc}
\hline Keterangan & Larva Mati \\
\hline Chi-Square & 175.282 \\
\hline df & 5 \\
\hline
\end{tabular}

Asymp. Sig $\quad 0,000$

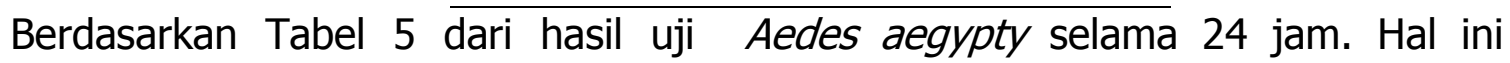
beda Kruskal Wallis berbagai konsentrasi menunjukkan bahwa setiap pemberian air perasan daun alpukat (Persea air perasan daun alpukat (Persea americana Mill.) terhadap kematian larva americana Mill.) dengan konsentrasi nyamuk Aedes aegypty dengan berbeda pada larva nyamuk Aedes perlakuan selama 24 jam diketahui aegypty mempengaruhi jumlah kematian mendapatkan nilai $P$ sebesar 0,000 dan larva.

$a=0,05$, maka $P \square 0,05$ (a) yang berarti ada perbedaan konsentrasi air perasan daun alpukat (Persea americana Mill.) terhadap kematian larva nyamuk
Berdasarkan hasil penelitian pada Tabel 3 menunjukkan bahwa semakin tinggi konsentrasi air perasan daun alpukat (Persea americana Mill.) yang 
diberikan pada larva nyamuk Aedes aegypty menyebabkan jumlah kematian larva yang semakin besar. Meningkatnya jumlah kematian larva pada konsentrasi yang lebih tinggi disebabkan oleh senyawa aktif daun alpukat yang masuk kedalam tubuh larva nyamuk Aedes aegypty semakin besar, sehingga proses senyawa aktif dalam merusak sistem tubuh fisiologi dan menghambat pertumbuhan larva yang menyebabkan kematian larva semakin cepat.

Senyawa-senyawa aktif untuk membunuh larva nyamuk Aedes aegypty tersebut meliputi alkaloid, flavonoid, saponin, dan tanin. Menurut Hasibuan (2015), golongan metabolit sekunder yang mempunyai bioaktivitas seperti insektisida antara lain adalah, alkaloids, fenols, flavonoids, glikosids, glikosinolats, kuinones, tanins, dan terpenoids. Berdasarkan uji pendahuluan pada air perasan daun alpukat (Persea americana Mill.) didapatkan hasil kandungan flavonoid $0,03 \%$, tanin $0,12 \%$, saponin $0,08 \%$, dan alkaloid $0,06 \%$. Hal ini menunjukkan bahwa senyawa kimia yang paling berpengaruh dalam menyebabkan kematian larva adalah tanin dan saponin karena memiliki presentase palng besar. Namun tidak menutup kemungkinan bahwa senyawa flavonoid dan alkaloid juga berpengaruh dalam menyebabkan kematian larva uji.

Berdasarkan kandungan senyawa aktif yang terdapat dalam daun alpukat yaitu flavonoid, tanin, saponin, dan alkaloid memiliki efek larvasida. Kandungan senyawa flavonoid sebagai racun pernapasan dan kandungan tanin, saponin, dan alkaloid sebagai racun perut memiliki daya bunuh terhadap kematian larva nyamuk Aedes aegypty. Larva nyamuk Aedes aegypti yang telah diberikan konsentrasi air perasan daun alpukat akan mengalami perubahan tingkah laku dimana gerakan yang sebelumnya aktif akan menjadi lamban, dan akhirnya akan mati. Larva Aedes aegypti dikatakan mati apabila larva tersebut sudah tidak bergerak bila disentuh dan berada di dasar air, serta tidak muncul lagi ke permukaan air. Larva yang mati nampak kelihatan putih pucat.

Dari hasil pengukuran faktor lingkungan pada aat penelitian dapat dikatakan bahwa $\mathrm{pH}$, suhu media air, suhu ruangan, dan kelembaban bukan merupakan faktor yang mempengaruhi tingkat kematian larva nyamuk Aedes aegypty dikarenakan sudah memenuhi kriteria faktor lingkungan yang kondusif utuk perkembangbiakan larva nyamuk Aedes aegypty, sehingga dapat dikatakan bahwa kematian larva nyamuk Aedes aegypty disebabkan oleh pemberian berbagai konsentrasi air perasan daun alpukat (Persea americana Mill.).

\section{Kesimpulan}

1. Hasil kematian larva nyamuk Aedes aegypty dengan pemberian berbagai konsentrasi air perasan daun alpukat (Persea americana Mill.) yaitu konsentrasi 7,5\%, 10\%, $12,5 \%$, $15 \%$, dan $17,5 \%$ yang diamati tiap jamnya selama 24 jam perlakuan menunjukkan kematian larva nyamuk Aedes aegypty paling rendah berada pada konsentrasi $7,5 \%$ dimana terdapat $61,3 \%$ larva 
yang mati dan kematian paling tinggi berada pada konsentrasi $15 \%$ dan $17,5 \%$ dimana terdapat $100 \%$ larva yang mati.

2. Nilai $L_{50}$ pada air perasan daun alpukat (Persea americana Mill.) yang dapat membunuh $50 \%$ larva nyamuk Aedes aegypty sebesar $10,624 \%$.

3. Terdapat perbedaan kematian larva nyamuk Aedes aegypty yang disebabkan oleh pemberian air perasan daun alpukat (Persea americana Mill.) dengan variasi konsentrasi $7,5 \%, 10 \%, 12,5 \%$, $15 \%$, dan $17,5 \%$ yang diamati tiap jamnya selama 24 jam perlakuan.

\section{E. Saran}

1. Bagi Instansi terkait agar dapat dijadikan alternatif lain untuk menekan jumlah populasi larva nyamuk Aedes aegypty sehingga dapat mengurangi jumlah kasus Demam Berdarah Dengue (DBD) selain menggunakan insektisida kimia.

2. Bagi masyarakat dapat menggunakan air perasan daun alpukat (Persea americana Mill.) sebagai biolarvasida dalam pengendalian vektor larva nyamuk Aedes aegypty.

3. Perlu dilakukan penelitan lebih lanjut mengenai waktu puncak senyawa aktif yang terdapat dalam air perasan daun alpukat (Persea americana Mill.) dalam membunuh larva nyamuk Aedes aegypty.

\section{DAFTAR PUSTAKA}

Arifin, Asrianti ,.dkk., 2013. Hubungan Faktor Lingkungan Fisik Dengan Keberadaan Larva Aedes Aegypty di Wilayah Endemis DBD di Kelurahan Kassi-Kassi Kota Makasar, http://repository.unhas.ac.id/bitstre am/handle/123456789/5544/JURN AL.pdf?sequence $=1$.(diakses 2 Januari 2018 pukul 09.00)

Boewono, D.T., et all, 2012. Distribusi Spasial Kasus Demam Berdarah Dengue (DBD), Analisis Indeks Jarak dan Alternatif Pengendalian Vektor di Kota Samarinda, Provinsi Kalimantan Timur. Media Litbang Kesehatan: 22.

Dinkes Jatim, 2017. Data Penderita Demam Berdarah Dengue (DBD) Provinsi Jawa Timur. Jawa Timur.

Dinkes Surabaya, 2016. Data Penderita Demam Berdarah Dengue (DBD) Kota Surabaya. Surabaya

Felix, 2008. Ketika Larva dan Nyamuk Dewasa Sudah Kebal Terhadap Insektisida. Farmacia, Vol. 7, No. 7.Gandham, Satish. 2013. Demam Berdarah dan Karakteristik Nyamuk Penyebar Demam Berdarah. The Indonesian Public Health Portal.

Hasibuan, Rosma, 2015. Insektisida Organik Sintetk dan Biorasional. Yogyakarta, Plantaxia : 87

Haditomo, Indriantoro, 2010. Efek Larvasida Ekstrak Daun Cengkeh (Syzygium aromaticum) Terhadap Aedes aegypti. Skripsi. Surakarta : Universitas Sebelas Maret.

Heriyanto, B., Damar Tri Boewono, Widiarti, Hasan Boesri, Umi Widyastuti, Blondine Ch.P., Hadi Suwarsono, Ristiyanto, Aryani Pujiyanti, Siti Alfiah, Dhian 
Prastowo, Yusnita Mirna Anggraeni, Anggi Septi Irawan, dan Mujiyono, 2011. Atlas Vektor Penyakit di Indonesia. Salatiga : Kementerian Kesehatan RI, Balai Besar Penelitian dan Pengembangan Vektor dan Reservoir Penyakit.

Laporan Departemen Kesehatan Republik Indonesia, 2017 http://www.depkes.go.id/download.p hp?file=download/pusdatin/infodatin infodatin\%20dbd\%202016.pdf (diakses 17 Desember 2018 pukul: 16.00)

Nugroho, Arif Dwi, 2011. Kematian Larva Aedes Aegypti Setelah Pemberian Abate Dibandingkan dengan Pemberian Serbuk Serai. Jurnal Kesehatan Masyarakat Vol. 7, No. 1 , Hal : 91-96. http://journl.unnes.ac.id/index.php/ kemas (diakses 9 Januari 2018 pukul 15.00)

Prasetyowati, H. Joni $H$. dan Tri W., 2016. Status Resistensi Aedes aegyty (Linn.) Organofosfat di Tiga Kotamadya DKI Jakarta. BALABA Vol. 12 No. 1 Hal: 23-30

Sukesi TW dan Surahma AM., 2007. Kerentanan NyamukAedes aegypti L. Terhadap Senyawa Organofosfat Temephos dan Malathion di Kelurahan Wirobrajan Kecamatan Wirobrajan Yogyakarta. Kesehatan Masyarakat. Hal: 21-26.

Sutanto, Inge, 2008. Parasitologi Kedokteran (Edisi Keempat). Jakarta. UI Press: Hal: 250-253. 